http://dx.doi.org/10.21707/gs.v11.n02a06

\title{
SANEAMENTo básico: DESINFORMAÇÃo COMO LiMitador do CONTROLE SOCIAL EM TERESINA-PI
}

\author{
José Machado Moita Neto ${ }^{1 *}$, Maria do Socorro Monteiro Carcara ${ }^{2}$
}

\author{
${ }^{1}$ Docente do Programa de Pós-graduação em Desenvolvimento e Meio Ambiente, Universidade Federal do Piauí \\ ${ }^{2}$ Discente do Doutorado do Programa de Pós-graduação em Desenvolvimento e Meio Ambiente, Universidade Federal do Piauí \\ *Autor para correspondência:jmoita@ufpi.edu.br
}

Recebido em 15 de fevereiro de 2016. Aceito em 22 de outubro de 2016. Publicado em 29 de julho de 2017.

\begin{abstract}
REsumo - O controle social foi delineado para o envolvimento de agentes informados e preparados para o planejamento, elaboração, implementação e avaliação das decisões governamentais. Em saneamento básico, é exigência da Lei 11.445/2007 e, no Plano Municipal de Saneamento Básico de Teresina, esta etapa consta como finalizada com êxito. Entretanto números desta pesquisa revelam uma população que ignora seu papel de protagonista nas ações de saneamento. Por falta de informação, não consegue reconhecer de maneira plena os problemas desta área, apesar de vivenciá-los diariamente. Além de fragilizar a cidadania, este corolário constitui sujeitos debilitados para a capacidade de cobrança por serviços que atendam a comunidade em que vivem.
\end{abstract}

Palavras-chave: Saneamento Básico; Participação; Controle Soclal; InFormação.

\section{BASIC SANITATION: DISINFORMATION AS A LIMITATION OF SOCIAL CONTROL IN TERESINA-PI}

ABstraCt - Social control was outlined for the involvement of informed and prepared agents for the planning, elaboration, implementation and evaluation of governmental decisions. In sanitation, social control is required by Law 11,445 / 2007 and the Municipal Sanitation Basic Plan for Teresina, this step is listed as successfully completed. However, results of this research reveal a population that ignores its role as protagonist in sanitation actions. Because they do not have information, the population can not fully recognize the problems of this area despite experiencing them daily. This context weakens citizenship and builds individuals with little capacity for charging for services that serve the community in which they live.

Keywords: BASIC SANITATION; PARTICIPATION; SOCLAL CONTROL; INFORMATION.

\section{SANEAMIENTo BÁSICO: LA DESINFORMACión COMO UNA LIMITACión DEL CONTROL SOCIAL EN TERESINA-PI}

RESUMEN - El control social se destaca por la participación de los agentes informados y preparados para la planificación, la elaboración, implementación y evaluación de las decisiones gubernamentales. En materia de saneamiento, el control social es requerido por la Ley 11.445 / 2007 y el saneamiento Plan de Saneamiento Municipal de Teresina, este paso está en la lista del completado con éxito. Sin embargo los números de esta investigación revelan una población que ignora su papel protagonista en acciones de saneamiento. Debido a que no tienen la información, no puede reconocer por completo los problemas de esta zona aunque experimentan a diario. Este corolario fragiliza la ciudadanía y produce sujeitos debilitados para una capacidad de cobranza por servicios para la comunidad.

Palabras Clave: Saneamiento; Participación; Control Soclal; Información. 


\section{INTRODUÇÃO}

A falta de saneamento básico adequado protagoniza o contexto das demandas na área de meio ambiente tanto nas grandes quanto nas pequenas cidades. Seja o aumento da incidência de enchentes; seja a dificuldade na gestão dos resíduos sólidos e o crescente despejo destes resíduos em áreas inadequadas; seja a inexistência de rede de esgotos, ou mesmo a soma de todos estes fatores, o que urge é a aplicação de políticas públicas que mitiguem impactos ao meio ambiente, à saúde da população, à economia do país e até mesmo na educação. Isso porque, conforme Moraes (2009), as ações de Saneamento Básico, além de fundamentalmente de saúde pública e de proteção ambiental, representam bens de consumo coletivo, serviços essenciais, direito social de cidadania, direito humano fundamental e dever do Estado.

Turolla (2002) recorda que o setor de saneamento organiza-se em boa parte do mundo sob o formato de gestão pública e local e que vários países desenvolvidos foram capazes de atingir a universalização quase absoluta sob esse modelo que não tem alcançado os mesmos índices no Brasil. Os dados mostram que a proporção de domicílios com saneamento adequado no Brasil subiu de 45,3\% em 1991 para 56,5\% em 2000 e 61,8\% em 2010. Nas cidades com até 5 mil habitantes estas proporções passaram de 9,7\% em 1991 para 21,7\% em 2000 e 30,8\% em 2010. Já nas cidades com mais de 500 mil habitantes, os percentuais eram de 73,6\% em 1991, 79,7\% em 2000 e 82,5\% em 2010 (IBGE, 2010). Regionalmente, as desigualdades se repetem. Enquanto no Sudeste 82,3\% dos domicílios possuem saneamento adequado, no Norte esta cobertura é de 22,4\%. Quando se parte para a população rural, verifica-se que sete em cada dez pessoas não conta com saneamento adequado.

Pesquisa Nacional por Amostras de Domicílios (PNAD) do ano de 2013 revelou que atrás apenas do Amapá (cujo índice era 3,2), no Piauí, a proporção de domicílios conectados à rede coletora de esgoto em 2013 era 3,4\%. Os índices são bem mais baixos que a terceira pior taxa, a do Maranhão, que era 13,2\%. Números do Ministério das Cidades, através do Sistema Nacional de Informações sobre Saneamento (SNIS), divulgado em dezembro de 2016, apontam que somente em 2015 a coleta de esgoto chegou a mais da metade da população, $50,3 \%$, e apenas 42,6\% dos esgotos gerados no país são tratados (SNIS, 2016).

Conforme o PMSB (2013), de um total de 210.093 domicílios analisados na área urbana de Teresina, 69,20\% têm acesso a saneamento de forma adequada, ou seja, com coleta de lixo, abastecimento de água e esgotamento sanitário ou fossa séptica. Já para o IBGE (2008), aproximadamente 39,30\% dos domicílios urbanos que possuem acesso ao saneamento ocorre de forma semi-adequada ${ }^{1}$. Em Teresina, na área urbana, o percentual de domićlios considerados inadequados é de $0,6 \%$. $\mathrm{Na}$ área rural, os números do saneamento adequado reduzem consideravelmente. Dos 12.061 domicílios verificados no censo de 2010, apenas 8,3\% enquadram-se na forma considerada adequada pelo IBGE, sendo que a maioria dos domicílios, 64,1\%, é considerada semi-adequada e $27,7 \%$ são classificados como inadequados. Os dados negativos revelam que a universalização dos serviços ainda é realidade distante.

As políticas públicas, independente da área, devem ser norteadas por princípios, pois são os seus pressupostos e balizadores. No caso do saneamento básico, são reguladas pela Lei 11.445/2007, que emergiu com o escopo de mitigar as disparidades no setor através do Plano Nacional de Saneamento Básico - Plansab, eixo central da atuação do Governo Federal, responsável pela definição de programas, ações e estratégias de investimento.

O Plansab elege o município como detentor soberano das ações de saneamento e anuncia o cidadão-

1 Forma semi-adequada significa que os domicílios têm acesso a, pelo menos, uma forma de saneamento considerada adequada. Quando o domicílio não tem nenhum acesso a saneamento, considera-se inadequado. 
usuário como protagonista da sua implantação, visto que é para ele que as ações devem convergir de maneira exitosa. Esta participação plena configura-se cidadania. Instituir o controle social é uma forma de democratizar a participação na aplicação de políticas públicas e, segundo Milani (2008), vincula-se com o movimento mais geral da sociedade brasileira na década de 80 , quando se intensificou essa proposta. Busca-se com a democratização, eliminar as formas autoritárias e tradicionais de gestão das políticas sociais, bem como a adoção de práticas que favoreçam uma maior transparência das informações e maior participação da sociedade no processo decisório. A participação social tornou-se, nos anos 1990, um dos princípios organizativos, aclamado por agências nacionais e internacionais, dos processos de formulação de políticas públicas e de deliberação democrática em escala local (Milani, 2008, p.552). Contudo na década de 70, Pateman (1970) já tratava sobre alternativas, teóricas e práticas, para o crescimento dos níveis de participação civil nos negócios públicos através da renovação de modelos de "democracia participativa".

Jacobi (2009) ajunta que, a participação dos cidadãos é uma forma de intervenção na vida pública com motivação social concreta que se exerce de forma direta, baseada num certo nível de institucionalização das relações Estado-Sociedade. Ele acentua que a análise das práticas participativas focaliza o estímulo da cidadania e abertura da gestão pública à participação da sociedade civil na elaboração de suas políticas públicas, assim como à complexa e contraditória institucionalização de práticas participativas inovadoras que marcam rupturas com a dinâmica predominante, ultrapassando as ações de caráter utilitarista e clientelista (Jacobi, 2009).

Controle social é um mecanismo fundamental de prevenção da corrupção e de fortalecimento da cidadania e deve ser entendido como a participação do cidadão na gestão pública, na fiscalização, no monitoramento e no controle das ações da Administração. Prevê a existência de um modelo de cidadãos e sujeitos coletivos, descrito por Milani (2008) como capazes de utilizar as regras e recursos existentes de modo reflexivo (ação reflexiva). Presume a existência de processos políticos que contemplem oportunidades de desenvolvimento das capacidades argumentativas dos cidadãos na definição da vontade coletiva e na elaboração institucional de espaços abertos à participação. "Os cidadãos são considerados enquanto sujeitos capazes de produzir a normatividade em que vivem; o Estado passa a ser a instância de organização e de legitimação dos processos políticos" (Blondiaux e Sintomer, 2002).

Quando se trata de saneamento básico, o controle social, que deve ser participativo em todas as etapas pressupõe, segundo Moisés et al (2010), um instrumento que contribui para a qualificação do gasto público em saneamento e a destinação eficiente dos recursos de forma a assegurar que sejam alocados e aplicados com eficácia e eficiência, revertendo em benefícios diretos à população, bem como na sustentabilidade dos serviços. Para a implantação da Política Nacional de Saneamento Básico, se fazem necessárias condições materiais para a participação e o controle social.

Assim sendo, "a participação social foi erigida em princípio político-administrativo para fomentar a participação dos diferentes atores sociais em sentido abrangente e criar uma rede que informe, elabore, implemente e avalie as decisões" (Milani, 2008, p.552).

Milani (2008) reitera ainda que a ênfase à necessidade de considerar-se a participação dos cidadãos nos processos de formulação e gestão das políticas públicas tornou-se uma resposta possível à crise do bem-estar e à necessidade de rever as relações entre o governo e a sociedade na definição de estratégias de desenvolvimento local. Contudo, este instrumento democrático apresenta entraves que dificultam sua aplicação. Em alguns contextos, a participação de atores diversificados é estimulada, mas nem sempre é vivida de forma equitativa. O 
autor conclui que o termo "parceria" é corriqueiro em discursos políticos governamentais e não-governamentais, mas sua prática efetiva parece ter dificuldades em influenciar os processos de deliberação democrática local.

Outro ponto levantado por Milani (2008) diz respeito à forma como os atores não-governamentais são consultados e solicitados durante o processo de tomada de decisões. Participando, assim e no melhor dos casos, somente antes e depois da negociação. "A participação praticada dessa forma pode aumentar a qualidade da transparência dos dispositivos institucionais; contudo, ela não garante, de modo necessário e automático, a legitimidade do processo institucional participativo na construção do interesse coletivo" (Milani, 2008, p. 555).

Pahl-Wostl (2002) resume que o processo participativo deve ser avalista da sustentabilidade das políticas ao reiterar que a governabilidade supõe a ampliação da participação da comunidade no processo de tomada de decisão sobre as políticas públicas, de tal forma que se construa um processo transparente de gestão pública, se estabeleça um ambiente no qual os prestadores de serviço se vejam na contingência de prestar contas de suas ações aos usuários e não-usuários e se criem condições para que os diversos interesses de grupos e segmentos sociais possam ser mediados.

O corolário até aqui aventado chama a atenção para a forma como se efetiva o processo de construção do interesse coletivo no âmbito dos dispositivos de participação e sobre as possibilidades de promover a democratização das políticas públicas via participação da sociedade em espaços de escassa infra-estrutura cívica e cidadã.

Nesta pesquisa, buscou-se identificar o acervo de conhecimentos da população de Teresina sobre saneamento básico, incluindo o controle social, que é determinante para a cidadania.

\section{Material e MÉtodos}

\section{Área de estudo}

O município de Teresina, capital do Estado do Piauí, está localizado na mesorregião Centro-Norte Piauiense, a 366 quilômetros do litoral, que constitui uma faixa de transição entre o Semiárido Nordestino e a Região Amazônica. Conforme dados do IBGE (2008), o seu território compreende uma área de 1.391,981 km². Desta, 17\% são consideradas urbanas e 83\% área rural de acordo com a Secretaria Municipal de Planejamento e Coordenação de Teresina (SEMPLAM). O território municipal é dividido geograficamente em quatro regiões: Norte, Sul, Sudeste e Leste.

Conforme Chaves e Lopes (2011) através de levantamento e análise de dados dos Censos Demográficos de 1980 a 2010 realizado por PMSB (2013) concluiu-se que, nas quatro últimas décadas, Teresina passou por intenso crescimento populacional. Em 1980 a população não chegava a 400 mil habitantes e, em 2010, passou a 814.230 habitantes.

Além do aumento populacional, as autoras revelaram que os impactos negativos ao meio ambiente urbano de Teresina são decorrentes do déficit de saneamento e da ocupação de áreas inadequadas, como margens de rios e lagoas, riachos, planícies fluviais, entre outras. Os problemas mais comuns destacados são as enchentes, causadas pelas ocupações das planícies fluviais e lacustres e que se tornaram freqüentes durante o período chuvoso. 
Métodos de coleta

Nesta pesquisa foi utilizado o Projeto de Levantamento, método detalhado por Crewell (2010) que descreve de forma quantitativa ou numérica tendências, atitudes ou opiniões de uma população. Através dele foi possível identificar o repertório de informações dos moradores de Teresina sobre saneamento básico e as fragilidades que eles reconhecem neste setor, bem como inferir sobre as informações sobre o controle social necessário para a implantação do Plano Municipal de Saneamento.

A pesquisa recorreu a uma amostra simples aleatória, em que o conjunto de dados é extraído ao acaso de uma população finita, com número previamente definido e entrevistados aleatoriamente escolhidos, de modo que em cada extração todos os elementos tenham a mesma probabilidade de seleção. A pesquisa tem nível de confiança de $95 \%$ e margem de erro de 10,35\%. Foram aplicados 90 questionários nas quatro zonas da cidade de Teresina: Norte, Sul, Sudeste e Leste, conforme modelo a seguir.

- Quais são as atividades que você considera como de saneamento básico?

- Tem esgoto?

- Aqui tem coleta de lixo?

- Quando chove, alaga?

- Tem água encanada?

- O senhor (a) tem conhecimento se a prefeitura já convidou alguém da sua comunidade para participar de reunião para sobre saneamento?

Os dados foram trabalhados pelo software Statistical Package for Social Science for Windows (SPSS) utilizado para análise estatística de dados.

Também foi realizada uma análise comparativa dos resultados obtidos na pesquisa com informações do Plano Municipal de Saneamento Básico de Teresina.

\section{Resultados discussão}

Os resultados apreendidos pela investigação são apresentados em três etapas. Inicialmente se verifica o grau de conhecimento que a população acumula sobre os quatro eixos de saneamento básico (Tabela 1), através da pergunta aberta: "Quais são as atividades que você considera como de saneamento básico?”. Requeria as seguintes respostas: água encanada, esgotamento sanitário, drenagem de águas pluviais, coleta e tratamento de resíduos sólidos.

Os próximos resultados (Tabela 2) descrevem como a população se sente atingida pelos problemas do setor, ao responder os questionamentos: "Aqui tem coleta de lixo?; Quando chove, alaga?; Tem água encanada?; Tem esgoto?".

Os dados seguintes (tabela 3) contemplam o quesito participação e investiga o grau de conhecimento sobre controle social.

Dos problemas mais reconhecidos de forma espontânea pela população como saneamento básico, desponta na liderança o esgotamento sanitário (57,8\%), seguido de coleta e tratamento de resíduos sólidos $(52,2 \%)$, abastecimento de água $(27,85 \%)$ e, por último, drenagem de águas pluviais $(4,4 \%)$. A falta de reconhecimento do problema de drenagem como saneamento pode ser um indício de que os entrevistados não conseguem 
desagregar o conceito de drenagem ${ }^{2}$ com o esgotamento sanitário ${ }^{3}$.

Tabela 1 - Atividades reconhecidas pelos entrevistados como saneamento

\begin{tabular}{lccc}
\hline \multicolumn{1}{c}{ Eixo } & Alternativa & Respostas & Porcentagem \\
\hline Abastecimento de água & NÃO & 65 & 72,2 \\
& SIM & 25 & 27,8 \\
Esgotamento sanitário & NÃO & 38 & 42,2 \\
& SIM & 52 & 57,8 \\
Coleta e tratamento de resíduos & NÃO & 43 & 47,8 \\
sólidos & & & \\
& SIM & 47 & 52,2 \\
Drenagem urbana & NÃO & 86 & 95,6 \\
& SIM & 4 & 4,4 \\
\hline
\end{tabular}

O maior número de resposta para esgotamento sanitário é justificado. Em Teresina, apenas 16,33\% da população possui coleta de esgoto; tendo como base os dados do Sistema Nacional de Informações sobre Saneamento do Ministério das Cidades, referentes ao ano de 2012. Com relação ao tratamento, apenas 14,7\% do esgoto da cidade passa por esse serviço.

A drenagem pluvial deveria ter sido evocada por mais entrevistados, tendo em vista que a falta de escoamento é um problema bastante evidente durante o período chuvoso - que geralmente vai de dezembro a abril - e que é responsável por situações de vulnerabilidade ambiental decorrente da ocupação das chamadas áreas de riscos, conforme assinalam Chaves e Lopes (2001). São essas ocupações de áreas de risco "que acabam por gerar os grandes problemas ambientais no meio urbano que afetam a cada ano mais e mais citadinos: as enchentes, os deslizamentos, os desmoronamentos de terras, dentre outros" (Chaves e Lopes, 2011. p.7).

Apesar de pouco mais da metade dos entrevistados terem identificado coleta de lixo e esgotamento sanitário, os número evidenciam reduzida informação sobre quais serviços compõem o saneamento básico e que pode ser atribuída à ausência de previsão de estratégias mais agressivas de divulgação dentro do plano de mobilização social do município. A desinformação sobre os serviços de saneamento se converte em enfraquecimento da etapa controle social, quando se parte do pressuposto que a falta de conhecimento debilita a aptidão da sociedade para a cobrança, além de reduzir a capacidade argumentativa durante as reuniões de controle social.

A tabela a seguir revela que tipo de problemas na área de saneamento básico a população entrevistada se sente mais atingida. Desta vez, as perguntas foram fechadas com os problemas sendo identificados. Neste grupo de perguntas, o entrevistado só precisaria responder SIM ou NÃO. A maioria deles (51,1\%) citou a drenagem de águas pluviais, elegendo-a, assim, como um dos principais problemas, seguido por coleta e tratamento de resíduos sólidos (4,4\%). Abastecimento de água e esgotamento sanitário ficaram empatados com 3,3\%.

O resultado da comparação das tabelas 1 e 2 apontam que a drenagem urbana, menos reconhecida pela população como serviço de saneamento tem grande percentual de identificação como problema da cidade. Pode-se depreender destes dados que o discrepante contraste entre os números da primeira pergunta (quando os entrevistados não reconhecem drenagem de águas pluviais como saneamento básico) com as respostas das últimas 2 Drenagem de águas pluviais é o composto de estruturas de engenharia destinadas ao transporte, retenção e disposição das águas das chuvas.

3 O sistema de esgotos sanitários é o conjunto de obras e instalações que propiciam- coleta; -transporte e afastamento; tratamento; disposição final das águas residuárias (esgotos gerados por uma comunidade ou por industrias) da comunidade, de uma forma adequada do ponto de vista sanitário. 
(que apontam a falta de drenagem como principal problema) conduz a inferir que a ineficiência da drenagem urbana, que leva a alagamentos no período chuvoso, pode ser entendida pela população como decorrência 'natural' da chuva e não como o despreparo das cidades em conviver com este evento e suas consequências. Novamente nos remete à conclusão de que o conhecimento sobre saneamento básico ainda é pouco difundido e que pode levar os gestores a preterir investimentos na área justamente pela falta de reivindicação popular. Chaves e Lopes (2011) reiteram que as áreas vulneráveis à inundação em Teresina, via de regra, são àquelas onde os setores censitários são chefiados, em sua maioria, por pessoas com baixos índices de renda, escolaridade e baixa cobertura de esgoto. Exatamente o público que postula serviços públicos de saúde, conforme pesquisa desenvolvida por Teixeira et al. (2014).

Tabela 2 - Atividades reconhecidas pelos entrevistados como saneamento

\begin{tabular}{lccc}
\hline \multicolumn{1}{c}{ Eixo } & Alternativa & Respostas & Porcentagem \\
\hline Abastecimento de água & NÃO & 3 & 3,3 \\
& SIM & 87 & 96,7 \\
Esgotamento sanitário & NÃO & 3 & 3,3 \\
& SIM & 87 & 96,7 \\
Coleta e tratamento de resíduos & NÃO & 4 & 4,4 \\
sólidos & & & \\
& SIM & 86 & 95,6 \\
Drenagem urbana & NÃO & 46 & 51,1 \\
& SIM & 44 & 48,9 \\
\hline
\end{tabular}

Esta parcela da população não associa que as condições de falta de investimento em saneamento a que está exposta são responsáveis por doenças temidas como a dengue a chikungunha e a zika. Segundo Carcará e Moita (2016), apesar do Estado se auto-isentar, ao atribuir ao mosquito e à população a responsabilidade por epidemia de doenças relacionadas ao Aedes aegypti - como dengue, chikungunha e zika vírus - a Organização das Nações Unidas (ONU) associou a proliferação do vetor às condições precárias de saneamento básico. Os autores justificam que, ao não ter acesso a serviços de saneamento, a população tende a armazenar água de maneira insegura, o que favorece a proliferação de mosquitos. Sistemas precários de esgotamento sanitário disposto em fossas inadequadas também resultam em água estagnada e foco de reprodução de vetores. Carcará e Moita (2016) acrescentam que as estruturas precárias de coleta e destinação de resíduos sólidos contribuem para que embalagens sejam descartadas de forma aleatória, o que permite que se transformem em foco de reprodução de vetores.

Desta forma, a desinformação fragiliza a capacidade de reivindicação do público, queéo mais recorrentemente acometido por verminoses, diarréias, disenterias, elefantíase, esquistossomose, febre amarela, febre tifóide, hepatite, infecções na pele e nos olhos, leptospirose, malária, poliomielite e muitas outras conhecidas doenças elencadas por Teixeira et al. (2014) que poderiam ser evitadas se não houvesse a ingestão de água contaminada, o contato da pele com o solo e lixo infectados, esgoto, água parada, resíduos sólidos, rios poluídos e outras situações que contribuem para o aparecimento de insetos e parasitas que podem transmitir doenças.

Apesar de a lei 11.445/2007 destacar conceitos como integralidade, universalidade e controle social, na prática, essa não é uma realidade em Teresina. Segundo o Plansab (2013), a noção de universalidade remete à possibilidade de todos os brasileiros poderem alcançar uma ação ou serviço de que necessite, sem qualquer 
barreira de acessibilidade, seja legal, econômica, física ou cultural. A integralidade, no caso do saneamento básico, é estabelecida pelo Plansab (2013) como o conjunto de todas as atividades e componentes de cada um dos diversos serviços de saneamento básico, propiciando à população o acesso na conformidade de suas necessidades e maximizando a eficácia das ações e resultados. Destarte, os números já expostos na introdução deste trabalho revelam que a universalidade ainda não se efetivou no município de Teresina. A integralidade ainda é mais remota, sendo a zona rural a região menos contemplada, onde apenas $8,3 \%$ das residências enquadram-se na forma considerada adequada pelo IBGE.

Para que se cobre a efetivação destes quesitos, a população precisa ter acesso a essas informações, o que os resultados desta pesquisa demonstram não ter. Segundo Chauí (1993), os sujeitos políticos participam da vida social em proporção ao volume e qualidade das informações que possuem, em especial, a partir das suas possibilidades de acesso às fontes de informação e de condições favoráveis de aproveitamento delas, de forma a poderem intervir como produtores do saber.

O Plano Municipal de Saneamento Básico de Teresina (PMSB) ressalta que as informações devem chegar às comunidades, como é previsto na Lei 11.445/2007, pois é o local previsto para que isto aconteça. Em seu conteúdo, consta que a equipe encarregada de elaborar o plano realizou reuniões, seminários, fóruns regionais e municipais, audiência pública e conferência, conforme tabela a seguir:

Quadro 1 - Agenda Geral das Atividades do PMSB de Teresina.

\begin{tabular}{|c|l|}
\hline Etapas & Atividades \\
\hline 1 & Reunião com Comitê de Coordenação e equipe municipal \\
\hline 2 & Seminário Municipal de Sensibilização sobre o PMSB \\
\cline { 2 - 3 } & Fóruns regionais \\
\cline { 2 - 2 } & Fóruns municipais \\
\hline 3 & Consulta Pública \\
\hline 4 & Fóruns regionais \\
\cline { 2 - 2 } & Fóruns municipais \\
\hline 5 & Consulta Pública através de página na internet \\
\hline 6 & Conferência Municipal de Saneamento Básico de Teresina \\
\cline { 2 - 2 } & Audiência Pública \\
\hline
\end{tabular}

Fonte: PMSB (2013)

O PMSB (2013) enumera os meios de comunicação utilizados para divulgação: cartazes, telefonia móvel, site "Pensar mais Teresina", rádios, avisos em escolas, postos de saúde e secretárias de atendimento público. "Considerando o alto índice de participação popular visto nas reuniões já realizadas, verifica-se que os meios de comunicação até o momento utilizados foram suficientes para divulgação dos fóruns municipais e das demais reuniões abertas à população (PMSB, 2013, p.137).

Contudo, as informações contidas no plano quando confrontadas com os números desta pesquisa apresentam disparidades. Sobre controle social, 93,3\% das pessoas entrevistadas disseram não ter conhecimento se o poder público municipal realizou reuniões. Ao responderem negativamente à pergunta "O (a) senhor (a) sabe se a Prefeitura de Teresina já convidou alguém da sua comunidade para reunião sobre saneamento básico?”, os entrevistados demonstram que não têm conhecimento se houve este convite, o que pressupõe que os mesmos não participaram e nem conhecem pessoas que participaram. 
Quando, no universo de pesquisados, apenas 6,7\% das pessoas respondem afirmativamente, depreendese que as estratégias do Plano de Mobilização Social (PMS) não obtiveram êxito e que os mecanismos de envolvimento da população e de conscientização do seu protagonismo na implantação desta política pública precisam ser repensados.

A informação encerra um domínio estratégico e político para os processos decisórios do controle social, fazendo-se necessário por parte dos sujeitos políticos envolvidos o efetivo conhecimento de todo o processo que envolve a implantação do saneamento básico para a transformação do agente popular em agente de planejamento, acompanhamento das ações, fiscalização e monitoramento dos serviços.

Blondiaux e Sintomer (2002) iteram a substancialidade de processos políticos que contemplem oportunidades de desenvolvimento das capacidades argumentativas dos cidadãos na definição da vontade coletiva e na elaboração institucional de espaços abertos à participação. Para os autores, os cidadãos são considerados enquanto sujeitos capazes de produzir a normatividade em que vivem; o Estado passa a ser a instância de organização e de legitimação dos processos políticos.

O desconhecimento dos entrevistados e a ausência destes nas reuniões realizadas em Teresina conduzem à conclusão de que participação não foi estimulada e nem executada de forma satisfatória e que o poder público precisa reelaborar estratégias que visem incentivar o processo de deliberação democrática local. Todavia, este trabalho não permite identificar se a falha na mobilização popular é inconsciente, se é fruto de inabilidade da equipe responsável por fomentá-la ou mesmo manipulada.

A manipulação no processo de participação social é histórica. Arnstein (1969) desenvolveu um modelo denominado "escada de Arnstein" (Quadro 2), citado em diversos trabalhos nacionais e internacionais, que apresenta, em um dos seus degraus, a manipulação como a "utilização", em nome da participação, de pessoas escolhidas para ocuparem cargos em comitês que funcionam como homologadores nas comissões consultivas.

Quadro 2 - Oito degraus da escada da participação-cidadã

\begin{tabular}{|c|l|l|}
\hline Degrau & Característica & Nível \\
\hline 8 & Controle Cidadão & Poder cidadão \\
\hline 7 & Delegação de Poder & Poder cidadão \\
\hline 6 & Parceria & Poder cidadão \\
\hline 5 & Pacificação & Concessão mínima de poder \\
\hline 4 & Consulta & Concessão mínima de poder \\
\hline 3 & Informação & Concessão mínima de poder \\
\hline 2 & Terapia & Não-participação \\
\hline 1 & Manipulação & Não-participação \\
\hline
\end{tabular}

Fonte: Arnstein (2002) ${ }^{4}$

Ao se examinar o número de desinformação sobre o controle social apontado por esta pesquisa, não se pode descartar a hipótese de que a efetividade do processo de realização de reuniões em Teresina coexista apenas no campo das formalidades, na conveniência de cumprimento das exigências legais.

Como em diferentes pesquisas brasileiras que versam sobre controle social (Piterman, Heler, Rezende (2013); Teixeira (2006); Assis (2003); Da Silva (2016)) é potencial o risco de estas reuniões serem engendradas 
no sentido de legitimar decisões verticais, ou seja, as de interesse da classe dominate. Isto pode acontecer de diversas formas: com a omissão da necessidade da participação popular em todas as fases do processo; pela maneira como as informações são dispostas, de forma a encaminhar para a legitimação dos interesses diferentes do que a comunidade carece; através da omissão de cenários; do levantamento ou descarte de hipóteses que corroborem com os interesses dos grupos dominantes, entre outras.

É patente uma investigação que examine também em que medida os atores sociais dispõem de informações que os tornem aptos a representar a comunidade nas reuniões, a influenciar efetivamente no sentido de melhorar o contexto social em que vivem, ou se terminam por ser, eles próprios, influenciados com os argumentos dos representantes das organizações governamentais durante estes encontros. Vale sublinhar que estes agentes oficiais são mais propensos a possuir conhecimentos técnicos, habilidades de oratória e persuasão, informações, dados, gráficos, argumentos mais embasados que terminam por inibir os representantes das comunidades, até pelo vocabulário que usam, pelos títulos que ostentam ou pela forma como se vestem.

Contudo, é fato que a instância popular é na verdade superior em um dos pontos mais relevantes do processo: o conhecimento da realidade local, da cultura e das necessidades individuais das famílias que compõem aquela coletividade. Fator este que a torna imprescindível para o sucesso da concretização da política pública.

Arnstein (2002) enfatiza que informar sobre direitos, responsabilidades e opções pode ser o mais importante primeiro passo rumo á legítima participação e cidadania. Mas que em reuniões em que a participação social deveria ser legítima, muito frequentemente se limitam a informações sendo repassadas em uma via de mão única, ou seja, dos técnicos para o cidadão, sem canal de retorno, e menos ainda sem que haja negociação, divulgando informações superficiais, desencorajando perguntas ou dando respostas evasivas. Essas características correspondem ao nível 3 da escada de participação-cidadã: Informação.

Entretanto, é no nível de concessão mínima de poder Consulta que esta pesquisa se permite enquadrar Teresina. Nesta categoria, os instrumentos mais utilizados são pesquisas de opinião, assembléias de bairro e audiências públicas, dispositivos utilizados para as deliberações sobre o Plano Municipal de Saneamento Básico da capital do Piauí e recomendados pelo Plansab. Porém Arnstein (2002) avalia que, quando os tomadores de decisão restringem as contribuições dos cidadãos apenas a este nível, a participação permanece apenas um ritual de fachada. Os participantes são vistos como abstrações estatísticas e a participação é medida pela quantidade de pessoas presentes nas reuniões, por quantos folhetos foram distribuídos ou quantas pessoas foram entrevistadas. "O que os cidadãos conseguem em todas estas atividades é que eles "participaram da participação". E o que os tomadores de decisão conseguem é a evidência de que eles cumpriram as normas de envolver "aquelas pessoas" (Arnstein, 2002, pp. 6 e 7).

Além do modelo de escada para descrever o grau participativo da sociedade apontado por Arnstein (1969), existem outros mais contemporâneos como o de Pretty (1995) que inspirou o paradigma de Heyd e Neef (2006). Em todos eles, no grau mais alto de participação, a população já exerce certa influência no processo decisório, em que o poder é transferido diretamente para a população, ficando esta responsável por todo o processo de decisão ou até mesmo de implantação da política pública, modelo este distante da realidade teresinense.

\section{CoNSIDERAÇõES FINAIS}

O que se discutiu até este ponto denota a necessidade de se contingenciar cenários para tentar responder o 
porquê das discrepâncias ente os números levantados pela pesquisa quantitativa realizada em Teresina por esta pesquisa e o conteúdo do Plano Municipal de Saneamento Básico da cidade no que se refere a controle social que, no escopo do PMSB, é mostrado como concluída com êxito. Contudo esta pesquisa revelou uma população incipiente sobre o tema, que não reconhece como fazendo parte das atividades de saneamento básico um dos principais problemas de infraestrutura da capital do Piauí, a drenagem urbana, muito menos que houve reuniões para elaborar um plano de saneamento para a cidade.

A desinformação sobre saneamento básico contribui para que as políticas não se efetivem em Teresina, tendo em vista que a população desconhece os serviços (esgotamento sanitário, drenagem urbana, abastecimento de água e tratamento e disposição de resíduos sólidos), não o reconhecendo como um sistema, tampouco sua relação com o meio ambiente, Saúde, Educação, Economia, bem estar e desenvolvimento. Os agentes sociais ignoram que devem ser, legalmente falando, protagonistas do processo, desde o planejamento até a regulação e que sua participação é fundamental para que a universalização e a equidade se tornem realidade em Teresina.

Enfim, alerta para a necessidade de sujeitos mais informados e críticos preparados para o exercício da cidadania e aptos a participar com mais segurança nos processos de decisões governamentais.

\section{REFERÊNCIAS}

Arnstein SR. 1969. A ladder of citizen participation. JAIP, v.35, n.4, p.216-224.

Arnstein SR. 2002. Uma escada da participação cidadã. Revista da Associação Brasileira para o Fortalecimento da Participação - Participe, Porto Alegre/Santa Cruz do Sul, v. 2, n. 2, p. 4-13.

Assis MMA. 2003. O processo de construção do controle social no Sistema Único de Saúde e a gestão nos espaços institucionais. Saúde em Debate v. 27, n. 65: 324-335.

Blondiaux L and Sintomer Y. 2002. L’impératif délibératif. Politix, v. 15, n. 57, p. 17-35.

Brasil. Lei $\mathbf{n}^{\circ}$ 11.445, de 5 de janeiro de 2007. Estabelece diretrizes nacionais para o saneamento básico; altera as Leis nos 6.766, de 19 de dezembro de 1979, 8.036, de 11 de maio de 1990, 8.666, de 21 de junho de 1993, 8.987, de 13 de fevereiro de 1995; revoga a Lei nº.528, de 11 de maio de 1978; e dá outras providências. Brasília, DF. Disponível em: http://www.planalto.gov.br/ccivil 03/ ato2007-2010/2007/lei/111445.htm. Acesso em 26 de dezembro de 2016.]

2015. Ministério das Cidades. Secretaria Nacional de Saneamento Ambiental. Plano Nacional de Saneamento Básico. Brasília, dez. 2013. Disponível em: < http://www.cidades.gov.br/images/stories/ ArquivosSNSA/Arquivos_PDF/plansab_06-12-2013.pdf $>$ Acesso em 30 de novembro de 2016.

2016. Secretaria Nacional de Saneamento Ambiental. Sistema Nacional de Informações sobre Saneamento (SNIS): diagnóstico dos serviços de água e esgotos -. Brasília, DF: Ministério das Cidades. Disponível em: http://www.snis.gov.br/diagnostico-agua-e-esgotos/diagnostico-ae-2015. Acesso em: 04 ago. 2017.

Carcará MSM e Moita Neto, JM. 2016. Análise da relação de causa e efeito entre saneamento básico e patologia 
relacionada ao aedes aegypti em matérias jornalísticas. Anais III Simpósio de Desenvolvimento do Trópico Ecotonal do Nordeste e I Simpósio de Desenvolvimento e Meio Ambiente (Simdema), 23 a 25 nov. Teresina, Piauí- Brasil. p.41 a 44.

Chauí MS. 1993. Cultura e democracia: o discurso competente e outras falas. 6ª Ed. São Paulo: Cortez. 376 p. Chaves SVV e Lopes WGR. 2011. A vulnerabilidade socioambiental em Teresina, Piauí, Brasil. Revista Geográfica da América Central. Número Especial EGAL, 2011. Costa Rica, pp. 1-17.

Creswell J.W. 2010. Projetos de pesquisa: métodos qualitativos e quantitativos. Porto Alegre. Artmed. 296 p.

Da Silva JMC. 2016. Controle Social das Políticas Públicas no Brasil. Revista Controle (Online), v. 8, n. 1, p. 71-90.

Heyd H and Neef A. 2006. Public participation in water management in northen Thai Highlands. Water Policy, v.8, n.5, p.395-413.

IBGE. Instituto Brasileiro de Geografia e Estatística. 2008. Pesquisa Nacional de Saneamento Básico. Disponível em:

< http://www.ibge.gov.br/home/estatistica/populacao/condicaodevida/pnsb2008/PNSB_2008.pdf> Acesso em: 04 dez. 2016.

2013. Instituto Brasileiro de Geografia e Estatística. Pesquisa Nacional de Amostra de Domicílios. PNAD. Disponível em: http://www.ibge.gov.br/home/estatistica/populacao/atlas_saneamento/default saneamento.shtm. Acesso em 14 dez. 2016.

Jacobi PR. 2009. Gestão democrática participativa no saneamento: conceitos e problematização. In: Brasil. Ministério das Cidades. Lei Nacional de Saneamento Básico: perspectivas para as políticas e gestão dos serviços públicos. Instrumentos das políticas e da gestão dos serviços públicos de saneamento básico. v. 1. Brasília: Ministério das Cidades. p. $103-113$.

Milani CRS. 2008. O princípio da participação social na gestão de políticas públicas locais: uma análise de experiências latino-americanas e européias. Rev. Adm. Pública. vol.42, n.3.p. 551-579.

Moises M et al. 2010. A política federal de saneamento básico e as iniciativas de participação, mobilização, controle social, educação em saúde e ambiental nos programas governamentais de saneamento. Ciênc. saúde coletiva [online]. vol.15, n.5. p 2581-2591.

Moraes LRS. 2009. Política e plano municipal de saneamento básico: aportes conceituais e metodológicos. In: Ministério das Cidades. Livro 1 - Instrumentos das políticas e da gestão dos serviços públicos de Saneamento Básico. D.F. Capítulo 1, p. 31-53.

Pahl-Wostl C. 2002. Towards sustainability in the water sector: the importance of human actors and processes of social learning. Aquatic Sciences, v. 64, p. 394 - 411. 
Pateman C. 1970. Participation and democratic theory. Cambridge: Cambridge University Press. 122 p.

Piterman A, Heller L e Rezende SC. 2013. (A falta de) Controle social das políticas municipais de saneamento: um estudo em quatro municípios de Minas Gerais. Saúde e Sociedade, v. 22, n. 4, p. 1180-1192.

PMSB. 2013. Plano Municipal de Saneamento Básico de Teresina: Produto 02 - Diagnóstico da Situação do Saneamento Básico. Disponível em:<http://semplan.teresina.pi.gov.br/wp-content/uploads/2015/05/ PMSB-DIAGNÓSTICO- -ATUALIZADO ABRIL.pdf>. Acesso em: 04 dez.2017.

Pretty J. 2006. Participatory learning and action: a trainer's guide. London: IIED, 1995. In: HEYD, H.; NEEF, A. Public participation in water management in northen Thai Highlands. Water Policy, v.8, n.5, p.395-413.

Souza C. 2011. A nova gestão pública. In: Gestão pública: desafios e perspectivas. Salvador: Fundação Luís Eduardo Magalhães, 2001. 103 p.

Teixeira EC. 2007. As dimensões da participação cidadã. Caderno CRH, Salvador, Editora Universidade Federal da Bahia, v. 10, n. 26,. Disponível em: . Acesso em: 23/10/2011.

Teixeira J et al. 2014. Estudo do impacto das deficiências de saneamento básico sobre a saúde pública no Brasil no período de 2001 a 2009. Eng. Sanit. Ambient.[online]. vol.19, n.1. Disponível em http://www.scielo.br/ pdf/esa/v19n1/1413-4152-esa-19-01-00087.pdf. Acesso em 25.dez.2016.

Turolla FA. 2002. Política de saneamento básico: avanços recentes e opções futuras de políticas públicas. Brasília: Ipea. 